\title{
Role of Notch, IL-1 and leptin expression in colorectal cancer
}

\author{
NILUFER ERKASAP ${ }^{1 *}$, RUMEYSA OZYURT $^{1 *}$, METE OZKURT $^{1 *}$, SERDAR ERKASAP $^{2}$, \\ FATIH YASAR ${ }^{2}$, ENVER IHTIYAR $^{2}$, EVRIM CIFTCI $^{3}$, FUNDA CANAZ $^{3}$ and ERTUGRUL COLAK ${ }^{4}$ \\ Departments of ${ }^{1}$ Physiology, ${ }^{2}$ General Surgery, ${ }^{3}$ Pathology and ${ }^{4}$ Biostatistics, \\ Eskisehir Osmangazi University Medical Faculty, Odunpazari, Eskisehir 26040, Turkey
}

Received September 15, 2020; Accepted March 11, 2021

DOI: $10.3892 / \mathrm{etm} .2021 .10032$

\begin{abstract}
An increasing number of studies have shown that angiogenesis has an important role in the progression of cancer. The growth of a new network of blood vessels is crucial for tumor growth and metastasis, which is promoted by several proangiogenic factors. Leptin, an essential adipokine that is secreted from fat tissue, is one of these pro-angiogenic factors. It has been shown that the inhibition of leptin-induced angiogenesis resulted in decreased levels of vascular endothelial growth factor (VEGF)/VEGFR2, hypoxia inducible factor (HIF) $1 \alpha$, NF- $\kappa$ B, IL-1 and Notch and reduced the tumor growth in breast cancer. Leptin induces angiogenesis in breast cancer either by upregulating VEGFR2 in endothelial cells or by increasing VEGF/VEGFR2 expression through the Notch, IL-1 and leptin crosstalk outcome (NILCO) pathway. NILCO is a novel mechanism that interacts with proinflammatory and proangiogenic signals, which are critical for cell proliferation and angiogenesis in cancer. Several studies have shown that components of NILCO may affect human cancer incidence and progression. However, to the best of our knowledge, the interactions between Notch, IL-1 and leptin in human colorectal cancer have not been yet studied at the molecular level. The aim of the present study was to investigate the expression levels of genes related to the NILCO pathway in human colorectal cancer specimens. The current results demonstrated that leptin, leptin receptor (ObR) b, Notch-1, Notch-4, IL-1 $\alpha$, IL-1 $\beta$, IL-1R, IL-6, JAK-2, STAT-1, STAT-3, VEGFA, VEGFR1, VEGFR2, TNF- $\alpha$ and NF- $\kappa$ B mRNA expression levels in the cancer tissue were increased compared with the normal tissue. No significant changes in the mRNA expression levels of Jagged-1, HIF-1 $\alpha$ and TNF receptor 1 were observed. Western blotting revealed that the protein expression levels of
\end{abstract}

Correspondence to: Professor Nilufer Erkasap, Department of Physiology, Eskisehir Osmangazi University Medical Faculty, Meselik Campus, Odunpazari, Eskisehir 26040, Turkey

E-mail: nerkasap@gmail.com

*Contributed equally

Key words: colorectal cancer, Notch, IL-1, leptin, Notch IL-1 and leptin crosstalk outcome
IкB were increased in the cancer tissue compared with normal tissue, whereas HIF-1 $\alpha$ and phosphorylated STAT-1 levels were decreased. IL-6 and VEGFA plasma concentrations were statistically raised and the leptin plasma concentration was also raised, although significantly, patients with cancer compared with control individuals. Together, the present findings indicated that Notch, IL-1 and leptin may serve a crucial role in the development of colorectal cancer.

\section{Introduction}

The proangiogenic effects of leptin, an essential adipokine secreted from fat tissue, have an important role in the development of cancer (1). It has been shown that the inhibition of leptin-induced angiogenesis results in decreased levels of vascular endothelial growth factor (VEGF)/VEGFR2, hypoxia inducible factor (HIF) $1 \alpha$, NF- $\kappa B$, IL-1 and Notch and reduced tumor growth in breast cancer $(2,3)$. Notch, as one of these target genes, affects various cell programs responsible for proliferation and apoptosis, thereby is essential for vasculogenesis and angiogenesis in cancer progression (3). It has been shown that leptin is one of the regulators of Notch expression in breast cancer. In addition, leptin induces the expression levels of IL-1 and VEGF/VEGFR2, as well as the expression levels of Notch1-4/Jagged-1/delta-like canonical Notch ligand (Dll) 4, which are important for the Notch signaling pathway. All these effects of leptin are related to the JAK-2/STAT-3 signaling pathway, the NF- $\kappa \mathrm{B}$ transcription factor, and HIF-1 $\alpha$, which is a key regulator of hypoxia response (4).

The interaction of IL-1, as another target gene, with leptin, has an important role in tumor inflammation, proliferation, and angiogenesis (5). IL-1 is a potent proinflammatory cytokine that influences tumor invasion and IL-1R expression levels are increased in tumor cells (6). Co-expression of IL-1R Type I, leptin/leptin receptor (ObR) and VEGF has been demonstrated in breast cancer (2).

Notch, IL-1 and leptin crosstalk outcome (NILCO) signaling, a novel mechanism that interacts with proinflammatory and proangiogenic signals, is critical for cell proliferation and angiogenesis in cancer $(4,7)$. Leptin mediates proangiogenic actions by upregulating VEGF/VEGFR 2 through the NILCO pathway $(3,8)$. The expression profiles of the mediators of the NILCO pathway have not been studied yet in detail in human colorectal cancer. The present study aimed to assess 
the NILCO pathway and the related gene and protein expression levels in human colorectal cancer tissues compared with normal colon tissue. In addition, leptin, IL-6 and VEGFA plasma concentrations were determined in cancer patients and in healthy individuals.

\section{Materials and methods}

Study subjects. The present study was approved by the Ethics Committee of Eskisehir Osmangazi University for Clinical Research (approval no. 80558721/90) and was performed following the ethical standards of The Helsinki Declaration. Tissue specimens from tumor and adjacent normal colon tissue $(n=40)$ were collected from the Department of General Surgery, Hospital of Eskisehir Osmangazi University, Eskisehir, Turkey. Healthy individuals were 25-50 years old without any disease. Written consent was obtained for the use of tissue and blood samples and for the publication of the derived data in the present study.

Tissue samples. In the present study, tumor and adjacent normal colon tissues from patients with colorectal cancer were collected between May 2017 and January 2018, and examined. All specimens were obtained during routine surgery performed in patients with colon cancer. Forty consecutive patients, aged 50 years or older, who underwent colectomy due to colon cancer were enrolled in the study after obtaining informed consent. Patients who had received neoadjuvant therapy and patients with diabetes, body mass index $>30 \mathrm{~kg} / \mathrm{m}^{2}$, coexisting or previous cancer history, and family history of colorectal cancer were excluded.

Besides the colorectal cancer tissues, macroscopically normal colonic tissues were obtained from the distal edge of the resection, which were confirmed as normal by pathologists at the Hospital of Eskisehir Osmangazi University. Samples approved by two pathologists were included in the study. Samples for which pathologists did not agree were excluded. Pathologists classified samples according to pathological type, tumor stage and metastasis status. Immediately after excision, tissue samples were fixed in RNAlater solution (Qiagen $\mathrm{GmbH}$ ) and stored at $-80^{\circ} \mathrm{C}$.

$R N A$ extraction and reverse transcription-quantitative PCR $(R T-q P C R)$. Total RNA was isolated from tumor and adjacent normal colon tissues using the GeneJet RNA Purification kit (Thermo Fisher Scientific, Inc.). The concentration and purity of the RNA were measured using a NanoDrop 1000 (Thermo Fisher Scientific, Inc.). The 260/280 values were 2.1, thus RNA purity was termed as good (9). Isolated RNA samples were converted to cDNA using the RevertAid First Strand cDNA Synthesis kit (Thermo Fisher Scientific, Inc.) at $42^{\circ} \mathrm{C}$ for $60 \mathrm{~min}$ and $70^{\circ} \mathrm{C}$ for $5 \mathrm{~min}$. cDNA samples were stored at $-80^{\circ} \mathrm{C}$ until further analysis. The mRNA expression levels of leptin, ObRb, Notch-1, Notch-4, IL-1 $\alpha$, IL-1 $\beta$, IL-1R, IL-6, JAK-2, STAT-1, STAT-3, VEGFA, VEGFR1, VEGFR2, TNF- $\alpha$, NF- $\kappa B$, Jagged-1, HIF-1 $\alpha$ and TNF receptor 1 (TNFR1) were measured using the SYBR Green qPCR kit (Thermo Fisher Scientific, Inc.). After $10 \mathrm{~min}$ at the $95^{\circ} \mathrm{C}$ activation period, the cycling conditions were $20 \mathrm{sec}$ at $95^{\circ} \mathrm{C}, 30 \mathrm{sec}$ at $55^{\circ} \mathrm{C}$ and $20 \mathrm{sec}$ at $72^{\circ} \mathrm{C}$, for 45 cycles. The $\beta$-actin gene was used as an internal control. Primer sequences are listed in Table I. Relative fold changes in mRNA expression were calculated using the formula $2^{-\Delta \Delta \mathrm{Cq}}(10)$.

Determination of leptin, VEGF, IL-1 and IL-6 plasma concentrations by ELISA. Plasma samples from healthy individuals and patients with colorectal cancer were stored at $-20^{\circ} \mathrm{C}$ until further analysis. Plasma leptin, VEGF, IL-1 and IL- 6 concentrations were determined using commercially available human-specific ELISA kits (VEGF, cat. no. BMS277/2; Invitrogen; Thermo Fisher Scientific, Inc.; Leptin, IL-1 and IL-6, cat. nos. KAP2281, KAP1211 and KAP1261, respectively; DIAsource ImmunoAssays SA), as recommended by the manufacturers. Optical density measurements were obtained using a plate reader system (Awareness Technology, Inc.).

Protein isolation and western blotting. Total protein was extracted from $100 \mathrm{mg}$ of tissue using M-PER Mammalian Protein Extraction Reagent, according to the manufacturer's instructions (Thermo Fisher Scientific, Inc.). The protein concentration was determined using a BCA Protein Assay kit (Thermo Fisher Scientific, Inc.). A total of $50 \mu \mathrm{g}$ per sample was separated by electrophoresis using Bolt ${ }^{\mathrm{TM}} 4-12 \%$ Bis-Tris Plus gels (Thermo Fisher Scientific, Inc.). The IBlot 2 Dry Blotting system (Thermo Fisher Scientific, Inc.) was used for the transfer to nitrocellulose membrane, according to the manufacturer's instructions. The blocking solution was prepared from the iBind ${ }^{\mathrm{TM}}$ Flex Solution kit (Thermo Fisher Scientific, Inc.) and the membrane was incubated in the blocking solution for $5 \mathrm{~min}$. After blocking, membranes were incubated with primary and secondary antibodies for $2 \mathrm{~h}$ on the iBind ${ }^{\mathrm{TM}}$ Flex Western device for $2.5 \mathrm{~h}$, according to the manufacturer's instructions (Thermo Fisher Scientific, Inc.). The $\beta$-actin antibody $(1: 1,000 ;$ cat. no. ab8227) was purchased from Abcam. Primary antibodies targeting Jagged-1 (1:500; cat. no. AP0531), STAT-1 (1:500; cat. no. A12075), STAT-3 (1:500; cat. no. A1192), JAK-2 (1:500; cat. no. A11497), HIF-1 $\alpha$ (1:500; cat. no. A11945), phosphorylated (p) STAT-1 (1:500; cat. no. AP0135), pSTAT-3 (1:500; cat. no. AP0070), pJAK-2 (1:500; cat. no. AP0531), IкB (a1:500; cat. no. A16929) and pIкB (1:500; cat. no. AP0614) were purchased from ABclonal Biotech Co., Ltd.. Anti-rabbit HRP-conjugated secondary antibodies used were purchased from Abcam $(1: 2,000$; cat. no. ab205718). Immunodetection was performed using chemiluminescence (West-Dura; Thermo Fisher Scientific, Inc.). The signal intensity was visualized on a ChemiDoc-It Imaging System (Bio-Rad Laboratories, Inc.), quantified by densitometry using ImageJ $1.49 \mathrm{v}$ (National Institutes of Health) and the means and SDs were calculated for each tissue type.

Statistical analysis. All statistical analyses were performed using GraphPad Prism version 6 (GraphPad Software, Inc.). To determine the tumor characteristics, one-sample $\chi^{2}$ tests were used. Descriptive statistics are reported as n (sample size), mean and SD for continuous variables, and as n (sample size), median and 25 and 75th percentiles for categorical variables. Continuous normally distributed measurements were compared across two groups by Student's t-test. Continuous 
Table I. Sequences of primers used in reverse transcription-quantitative PCR.

\begin{tabular}{|c|c|c|}
\hline Gene & Forward primer $\left(5^{\prime}-3^{\prime}\right)$ & Reverse primer $\left(5^{\prime}-3^{\prime}\right)$ \\
\hline Leptin & ACAGAAAGTCACCGGTTTGG & GCTCTTAGAGAAGGCCAGCA \\
\hline $\mathrm{ObRb}$ & AGGACGAAAGCCAGAGACAACC & GCCTGGGCCTCTATCTCCCA \\
\hline IL-1 $\alpha$ & CTTCTGGGAAACTCACGGCA & AGCACACCCAGTAGTCTTGC \\
\hline IL-1 $\beta$ & CCTGAGCTCGCCAGTGAAAT & GTCGGAGATTCGTAGCTGGA \\
\hline IL-1R & TGTGGTCCCTGTGTAAAGTCC & TGCCTGAGGTCTTGGAAAAAC \\
\hline IL-6 & СТТСТССАСАААСАТGTAACAAGAG & TTTCACCAGGCAAGTCTCCTC \\
\hline STAT-1 & TGCTGAGGTTTAGCTGTCAGT & AAGTCTCTTGGCTAGTGCAG \\
\hline HIF-1a & ACTTGGCAACCTTGGATTGGA & GTGCTGAGTAACCACCACTTA \\
\hline STAT-3 & GGCATTCGGGAAGTATTGTCG & GGTAGGCGCCTCAGTCGTATC \\
\hline$\beta$-actin & GGACTTCGAGCAAGAGATGG & AGCACTGTGTTGGCGTACAG \\
\hline TNF- $\alpha$ & CACAGTGAAGTGCTGGCAAC & GATCAAAGCTGTAGGCCCCA \\
\hline TNFR1 & ACCAAGTGCCACAAAGGAAC & CTGCAATTGAAGCACTGGAA \\
\hline $\mathrm{NF}-\kappa \mathrm{B}$ & AGGACGTGGAGTCAGGCTAT & TCTTGAGAAGGCTCAGCAGC \\
\hline VEGFA & TGTCTAATGCCCTGGAGCCT & TTAACTCAAGCTGCCTCGCC \\
\hline Notch-1 & TCCTAGTTTGGGAGGAGCAGA & CACTGGCATGACACACAACAG \\
\hline Notch-4 & GGATCCCCCAAAATGAAGGG & TCTGCTCTGGTGGGCATACA \\
\hline Jagged-1 & GCACGCGTCATTGTGTTACC & GCGCAGCCTTTTATTCCCTT \\
\hline JAK-2 & TGAGTTCGAAGCTAGCAGGG & AAGCCCGTCACAGTTGTCTC \\
\hline VEGFR1 & GCTGTTTTCTCTCGGATCTCCA & TCCGAGCCTGAAAGTTAGCA \\
\hline VEGFR2 & CGGTCAACAAAGTCGGGAGA & CAGTGCACCACAAAGACACG \\
\hline
\end{tabular}

ObRb, leptin receptor B; HIF, hypoxia inducible factor.

variables that did not show normal distribution were compared by the Mann-Whitney U-test. $\mathrm{P}<0.05$ was considered to indicate a statistically significant difference.

\section{Results}

Patient characteristics. Patient demographic data and tumor characteristics are listed in Table II.

Tumor staging findings. Tissues from patients with T2, T3 and T4 stage cancer were included in the present study. Individuals with $\mathrm{T} 1$ stage cancer are not taken into operation. One-sample $\chi^{2}$ tests were used to determine the difference between T2, $\mathrm{T} 3$, and $\mathrm{T} 4$ distributions of tumor stages in patients. In this analysis, the expected frequency for each stage would be $40 / 3$, therefore 13.33 samples for each stage. The P-value obtained as a result of the chi-square test analysis was $\mathrm{P}<0.001$. This finding indicated that the distribution of tumor stages in patients was not equal and that the patients were mostly at the T3 stage (Fig. S1A).

Tumor pathological findings. To detect the difference in the distribution between the tubular adenocarcinoma and mucinous carcinoma type in the patients, a one-sample Chi-square test was applied. In this analysis, the expected frequency for each type would be 40/2, therefore 20 samples per cancer type. The $\mathrm{P}$-value obtained as a result of the analysis was $\mathrm{P}<0.001$. According to this result, the distribution of pathological types was not equal and most patients were presented with tubular adenocarcinoma (Fig. S1B).
Tumor localization findings. To determine the difference in the distribution between the right colon, left colon, sigmoid colon, cecum and rectum tumor localization in the patients, a one-sample chi-square test was used. In this analysis, the expected frequency for each site could be assumed to be equal. The P-value obtained as a result of the analysis was $\mathrm{P}=0.199$. According to this result, the tumor localization distribution in patients was found to be equal (Fig. S1C).

Gene expression levels. RT-qPCR analyses revealed that Notch-1 and Notch-4 mRNA expression levels were greater in cancer tissues compared with normal tissues (Fig. 1A and B), while no difference in Jagged-1 mRNA levels was observed (Fig. 1C).IL-1 $\alpha$, IL-1R, IL-1 $\beta$ and IL-6 mRNA expression levels were greater in cancer tissues compared with normal tissues (Fig. 2). Leptin, ObRb, JAK-2, STAT-1 and STAT-3 mRNA expression levels were greater in cancer tissues compared with normal tissues (Fig. 3). Additionally, VEGFA, VEGFR1 and VEGFR2 mRNA expression levels were greater in cancer tissues compared with normal tissues (Fig. 4). Finally, TNF- $\alpha$ and $\mathrm{NF}-\kappa \mathrm{B}$ mRNA expression levels were greater in cancer tissues compared with normal tissues (Fig. 5A and B), while HIF-1 $\alpha$ and TNFR 1 mRNA expression levels were unchanged (Fig. 5C and D).

Protein expression levels. Western blot analyses revealed that Jagged-1 protein expression levels were not significantly different in tumor tissues compared with normal tissues (Fig. 6). JAK-2, pJAK-2, STAT-1, STAT-3 and pSTAT-3 protein expression levels were unchanged between tumor tissues and 
Table II. Patient demographic data and tumor characteristics.

\begin{tabular}{lc}
\hline Clinicopathological feature & Number of patients \\
\hline Sex & \\
Female & 22 \\
Male & 18 \\
Average weight $(\mathrm{kg})$ & 73 \\
Average height $(\mathrm{cm})$ & 165 \\
Tumor localization & \\
Right colon & 5 \\
Left colon & 6 \\
Sigmoid colon & 13 \\
Cecum & 5 \\
Rectum & 11 \\
Pathologic type & \\
Tubular adenocarcinoma & 35 \\
Mucinous carcinoma & 5 \\
TNM classification & \\
T2 & 2 \\
T3 & 53 \\
T4 & 5 \\
Lymph node metastasis & \\
N1 & \\
N2 & 7 \\
Distant metastasis & \\
M0 & \\
M1 & \\
& \\
&
\end{tabular}

The American Joint Committee on Cancer 8th TNM staging system was used to stage the tumors. TNM, tumor node metastasis.

normal tissues (Fig. 7), and only pSTAT-1 protein levels were significantly decreased in tumor tissues compared with normal controls (Fig. 7). Of note, total I $\mathrm{B}$ protein expression levels were increased in tumor tissues compared with normal tissues, while pIкB protein levels were unchanged (Fig. 8). Finally, HIF-1 $\alpha$ protein expression levels were significantly decreased in tumor tissues compared with normal controls (Fig. 8).

Leptin, IL-1 $\beta, I L-6$, and VEGFA plasma concentrations. ELISA analyses revealed that leptin plasma concentration was somewhat increased in patients with colorectal cancer, albeit the result was not statistically significant (Fig. 9A). IL-1 $\beta$ plasma concentration was unchanged in patients with colorectal cancer compared to healthy individuals (Fig. 9B). Notably, IL-6 and VEGFA plasma concentrations were significantly increased in patients with colorectal cancer compared to healthy individuals (Fig. 9C and D).

\section{Discussion}

Analysis of the patient cohort used in the present study revealed that the histologic types and tumor grades of the adenocarcinomas were not evenly distributed. The patients had mostly
T3 tubular adenocarcinomas, thus the present results were predominantly attributable to this particular group of patients. It has been shown that leptin levels are increased in multiple types of cancer, including colorectal carcinomas (11-13). Effects of leptin are mediated by multiple signaling pathways, including the JAK-2/STAT-3 pathway. STAT-3 contributes to oncogenesis by stimulating cell cycling and inhibiting apoptosis. Endo et al (14) suggested that leptin may promote the progression of colorectal cancer through the ObRb/STAT-3 pathway. This previous report found a marked increase of ObR expression levels in colon tumors compared with normal epithelium (14). In the present study, leptin, ObR, JAK-2, STAT-1, and STAT-3 mRNA expression levels in colorectal tumor tissues were greater compared with normal colon tissues. Of note, the leptin protein levels in the blood samples of the patients with colorectal cancer were not changed. The correlations between mRNA and protein concentrations are typically poor. Furthermore, it is unclear to what extent the relative concentration differences on the mRNA level are transferred to the protein level (15).

The present results, which are mainly consistent with previously published literature, demonstrated that adipokines are closely related to tumorigenesis. Additionally, leptin and IL-1-induced signals, which collaborate in many pathologic states, have important roles in inflammation, proliferation, and angiogenesis (7).

The IL-1 family of cytokines have proinflammatory and angiogenic properties. The expression of IL-1 is associated with an aggressive phenotype of breast cancer, while in vitro studies have revealed that IL-1 may influence progression and metastasis of lung cancer, colorectal cancer, and malignant melanoma (5). The current study has shown that the mRNA expression levels of IL- $1 \alpha$ and IL-1 $\beta$ were increased in the cancer tissues compared to the normal tissues. In cancer patients, IL-6 plasma levels were significantly elevated compared with the control group.

IL-1 is a potent leptin inducer and IL-1 receptor type 1 (IL-1R TypeI) partially mediates the effects of leptin (16). Immunohistochemical analyses have shown that IL-1R TypeI, leptin/ObR, and VEGF are coexpressed in cancer cells (2), which indicates that the interaction of leptin and IL-1 may have an important role in angiogenesis and tumor progression. Consistent with these findings from previous studies, the current study has demonstrated that IL-1R TypeI mRNA expression levels were greater in the cancer tissues compared with the normal tissues.

The Notch signaling pathway is crucial in colorectal cancer progression, as well as in self-renewal and homeostasis of the normal intestinal epithelium (17). Notch signaling regulates the balance between cell proliferation, differentiation, and apoptosis $(18,19)$. This pathway has a key role in tumor angiogenesis and is associated with worse prognosis and survival in cancer patients. Ligands and receptors of Notch are membrane-bound proteins (3). The expression of both the Notch-1 and Notch-2 receptors and of the Jagged-1 ligands have been demonstrated to be increased in colorectal cancer cell lines (20). In the present study, Notch-1 and Notch-4 mRNA expression levels in the cancer tissues were increased compared with the normal tissues, but the expression levels of Jagged-1 were unchanged. 

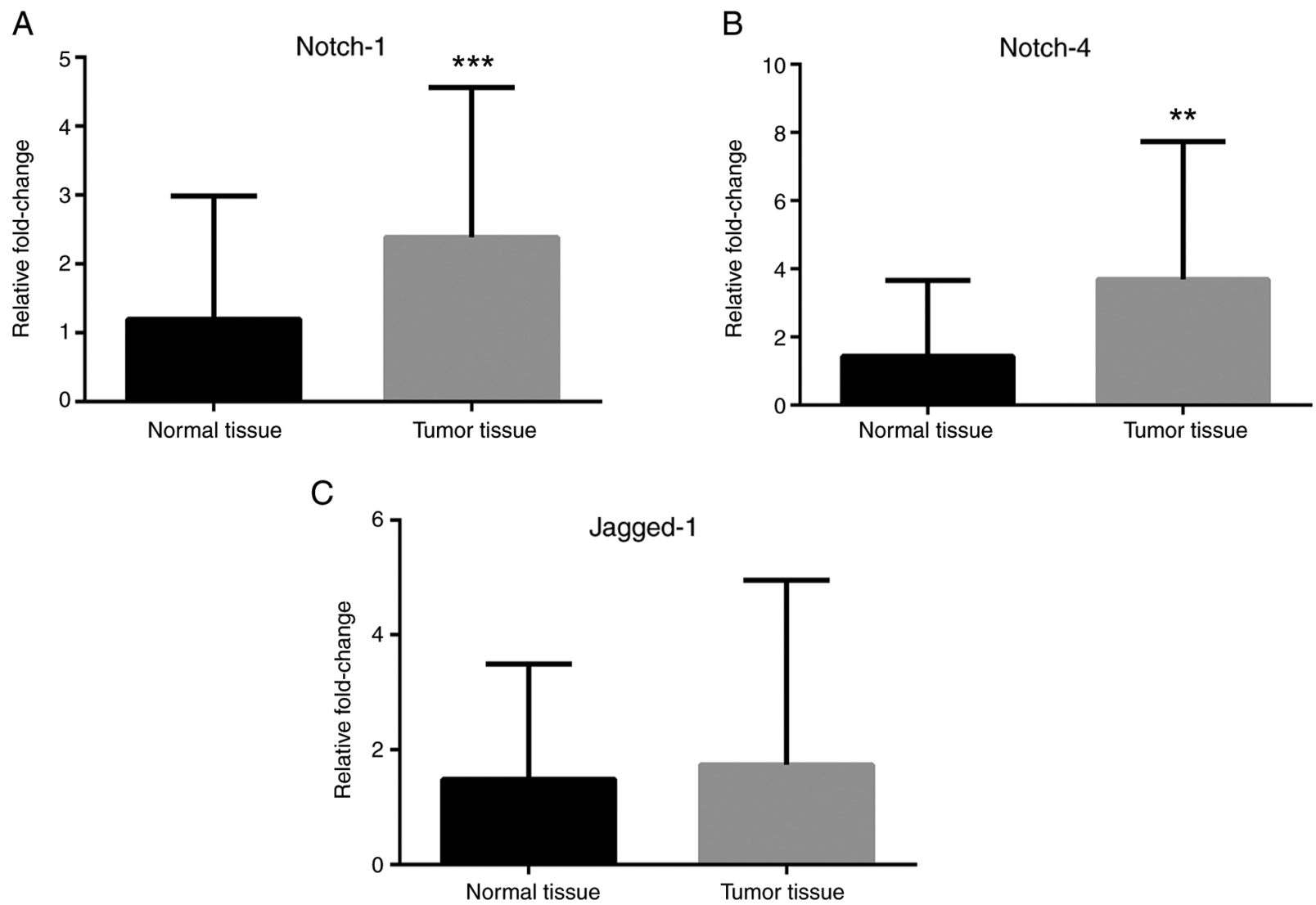

Figure 1. Expression of Notch pathway-associated genes in colorectal cancer tissues. mRNA expression levels of (A) Notch-1, (B) Notch-4, and (C) Jagged-1 in tumor tissues compared with normal tissues. $\beta$-actin was used as an internal control. Data (mean $\pm \mathrm{SE}$ ) are representative results derived from a minimum of three independent experiments. ${ }^{* *} \mathrm{P}<0.01$ and ${ }^{* * * *} \mathrm{P}<0.001$.

A

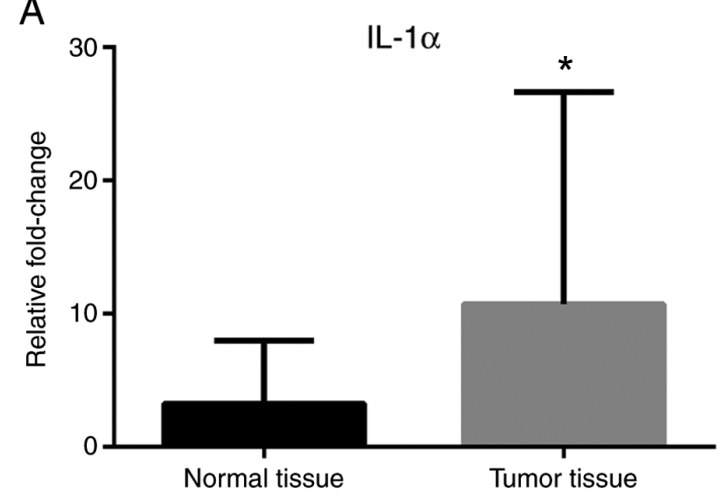

C

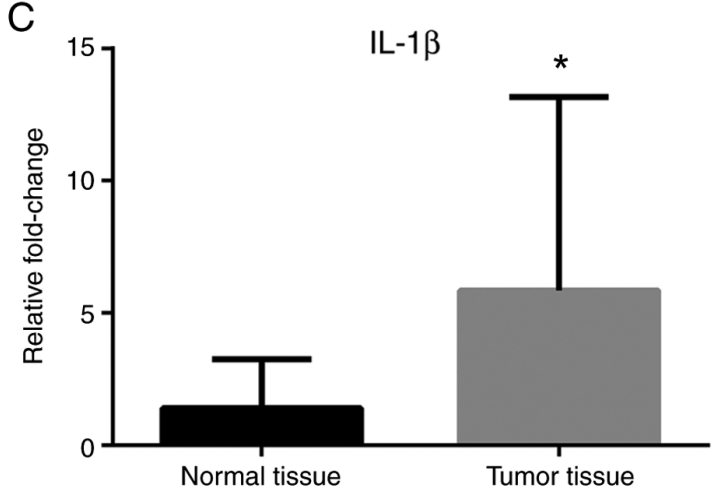

B

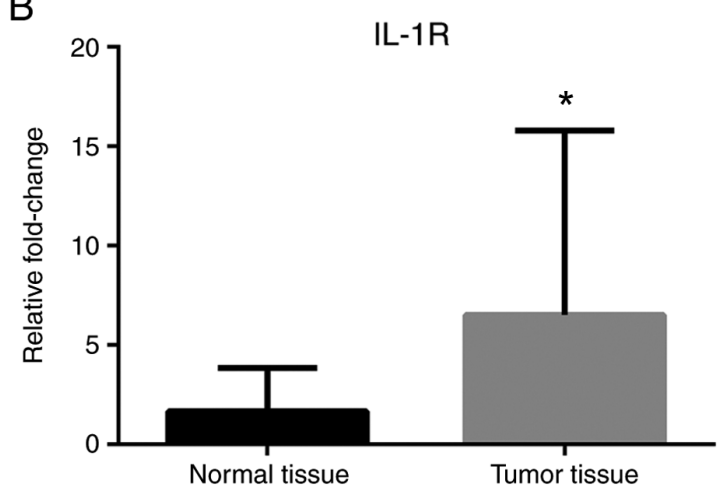

D

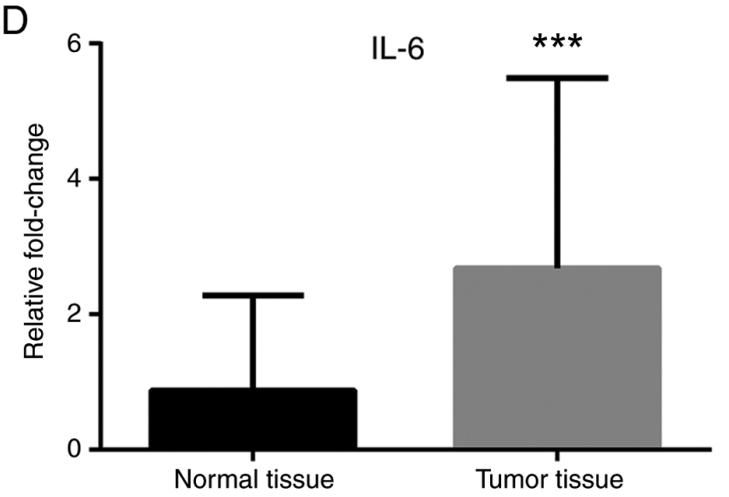

Figure 2. Expression of interleukin pathway-associated genes in colorectal cancer tissues. mRNA expression levels of (A) IL-1 $\alpha$, (B) IL-1R, (C) IL-1 $\beta$ and (D) IL-6 in tumor tissues compared with normal tissues. $\beta$-actin was used as an internal control. Data (mean \pm SE) are representative results derived from a minimum of three independent experiments. ${ }^{*} \mathrm{P}<0.05$ and ${ }^{* * *} \mathrm{P}<0.001$. IL, interleukin, $\mathrm{R}$, receptor. 

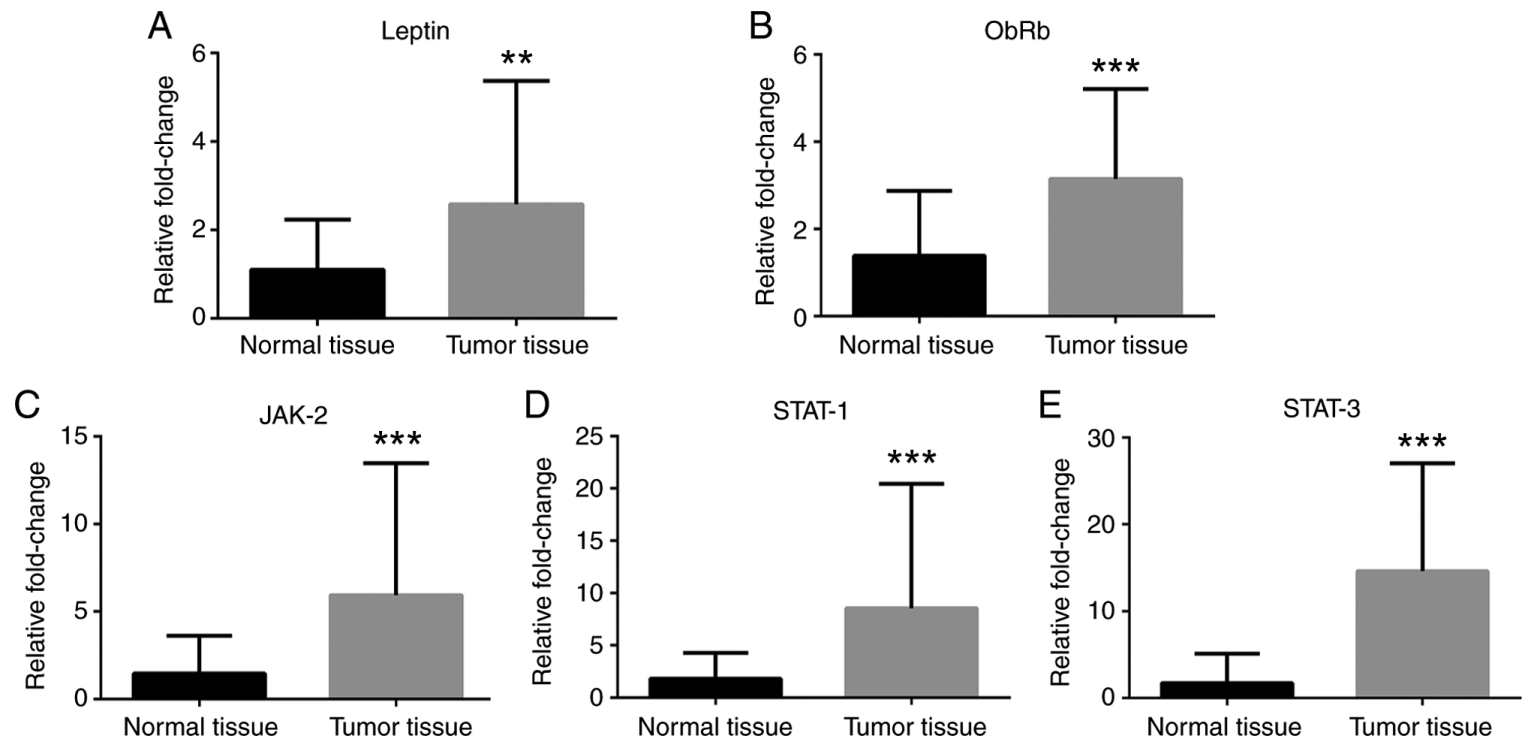

Figure 3. Expression of leptin and JAK/STAT pathway-associated genes in colorectal cancer tissues. mRNA expression levels of (A) leptin, (B) ObRb, (C) JAK-2, (D) STAT-1 and (E) STAT-3 in tumor tissues compared with normal tissues. $\beta$-actin was used as an internal control. Data (mean \pm SE) are representative results derived from a minimum of three independent experiments. ${ }^{* *} \mathrm{P}<0.01$ and ${ }^{* * *} \mathrm{P}<0.001$. ObRb, leptin receptor $\mathrm{B}$.
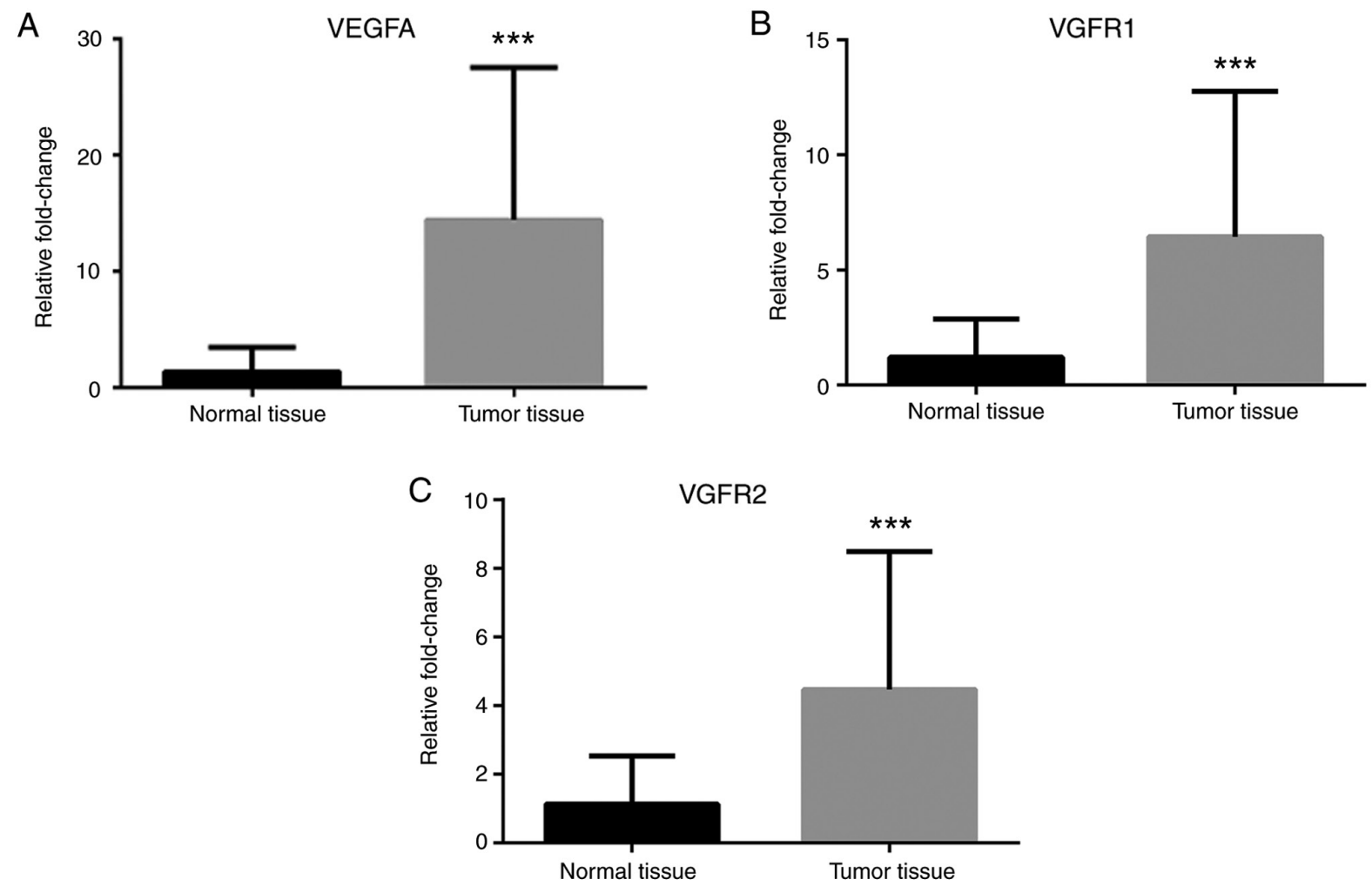

Figure 4. Expression of VEGF pathway-associated genes in colorectal cancer tissues. mRNA expression levels of (A) VEGFA, (B) VEGFR1, and (C) VEGFR2 in tumor tissues compared with normal tissues. $\beta$-actin was used as an internal control. Data (mean \pm SE) are representative results derived from a minimum of three independent experiments. ${ }^{* * *} \mathrm{P}<0.001$.

Previous studies have reported that leptin is a regulator of Notch expression in breast cancer. In addition, leptin induces the expression of IL-1 and of VEGF/VEGFR2, as well as the expression of Notch1-4/Jagged-1/Dll-4 (4). This information indicates that NILCO may serve an essential role in the progression of cancer. NILCO emerges as a mechanism that induces cell proliferation and activates proangiogenic and proinflammatory pathways, thus serving a crucial role in the progression of different types of cancer $(4,7)$.

Leptin mediates proangiogenic actions either by transactivating VEGFR2 independent of VEGF or by upregulating VEGF/VEGFR2 through the NILCO pathway (3). In the present study, the results demonstrated that the mRNA expression levels of VEGFA, VEGFR1, and VEGFR2 and 
A

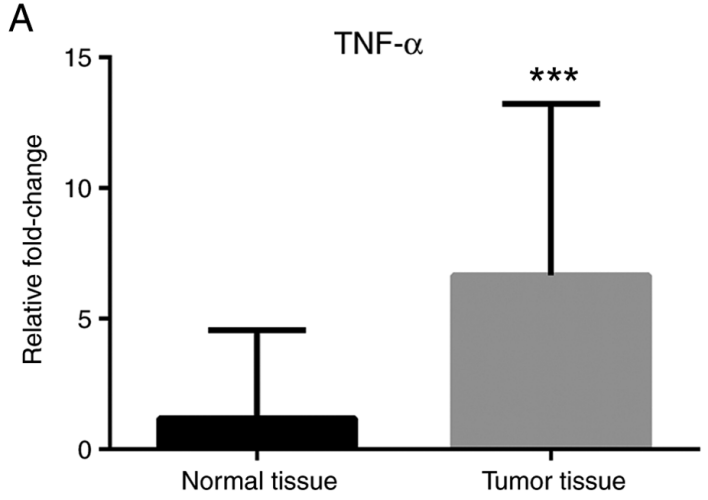

C

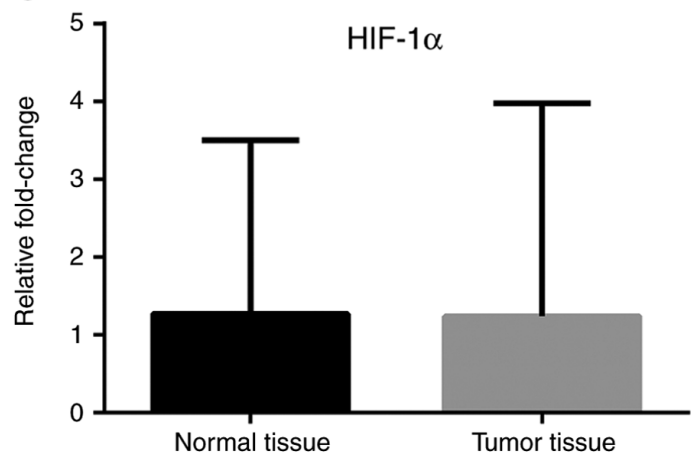

B

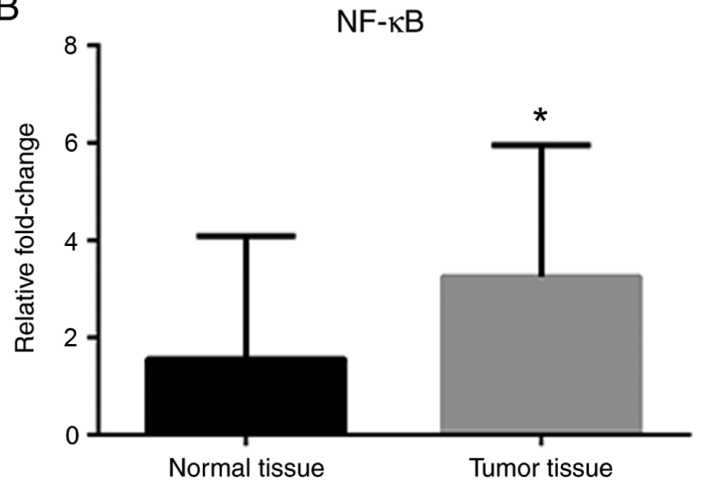

D

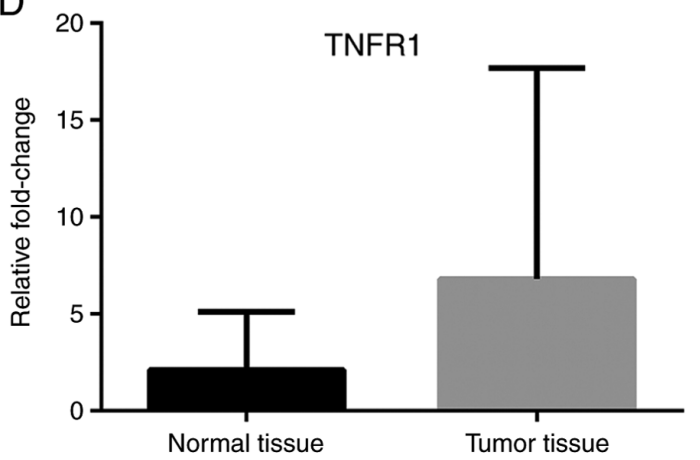

Figure 5. Expression of TNF- $\alpha$, NF- $\kappa$ B and HIF-1 $\alpha$ genes in colorectal cancer tissues. mRNA levels of (A) TNF- $\alpha$, (B) NF- $\kappa$ B, (C) HIF-1 $\alpha$, and (D) TNFR1 in tumor tissues compared with normal tissues. $\beta$-actin was used as an internal control. Data (mean \pm SE) are representative results derived from a minimum of three independent experiments. ${ }^{*} \mathrm{P}<0.05$ and ${ }^{* * *} \mathrm{P}<0.001$. HIF, hypoxia inducible factor.
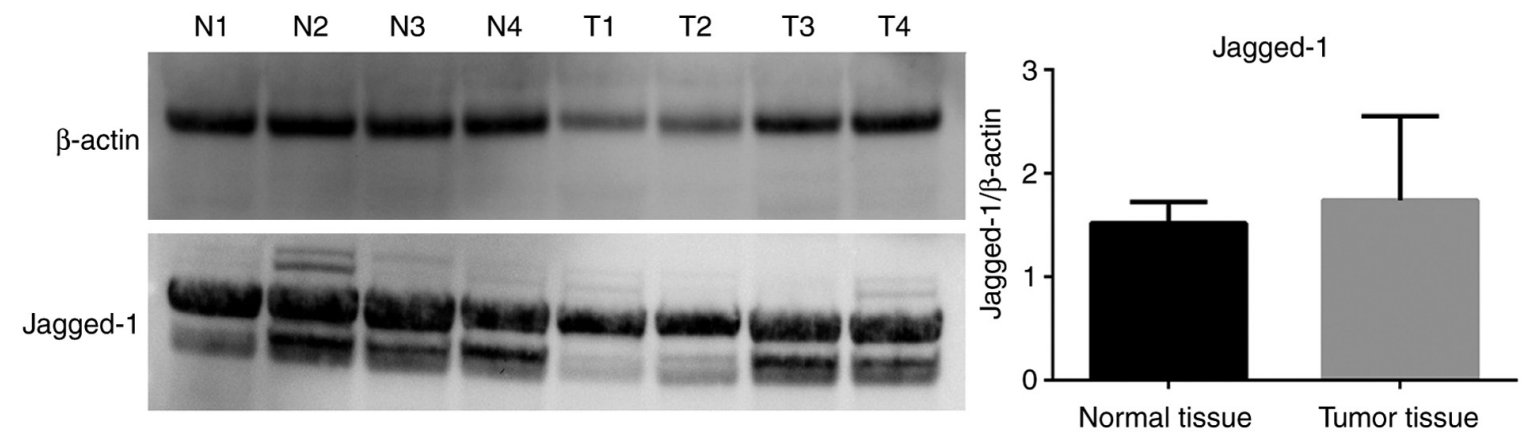

Figure 6. Jagged-1 protein levels in colorectal cancer tissues. The protein expression levels of Jagged-1 in normal and tumor tissues were determined by western blotting. $\beta$-actin was used as a loading control. Data (mean $\pm \mathrm{SE}$ ) are representative results derived from a minimum of three independent experiments.

the blood VEGFA protein levels were increased, which suggests that leptin in cancer tissues may have proangiogenic properties.

The increase in the levels of angiogenic factors, such as TNF- $\alpha$, VEGF, IL-1, IL- 6 and leptin, indicated an increase in the extent of angiogenesis. In the present study, the increase in VEGF, IL-1, IL-6, leptin and ObRb mRNA expression levels is consistent with the previous literature and confirms that these genes contribute to the progression of cancer (3).

It has been found that $\mathrm{ObRb}$ is expressed in human lung cancer A549 and H157 cells and leptin release increases the production of immuno-inflammatory cytokines, such as IL-6, VEGF and prostaglandin (21). Angiogenesis is an extremely important process contributing to the progression of cancer. The growth factor VEGF released from endothelial cells has an important role in angiogenesis. Since VEGF plays a role in tumor angiogenesis as well as proliferation, invasion and metastasis of tumor cells, it is one of the main targets in cancer treatment (3). According to these two studies, the relationship between leptin, IL-6 and VEGF plays an important role in cancer development and prognosis. This information is in line with the results of the present study, where leptin, IL-6 and VEGF levels were significantly increased in cancer tissues. In addition, hypoxia induces angiogenesis, through the transcriptional activity of $\mathrm{HIF}-1 \alpha$. It has been reported that hypoxia-induced HIF-1 $\alpha$ is associated with an increase in the levels of leptin and VEGF expression levels in breast cancer. (3). By contrast, there was no significant change in the mRNA expression levels of HIF-1 $\alpha$ in the present study. 

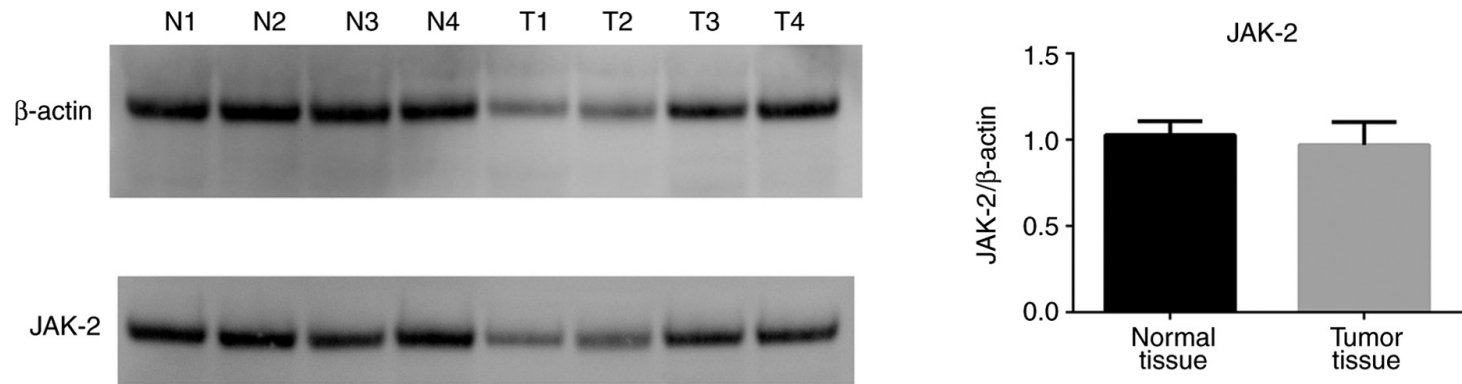

pJAK-2
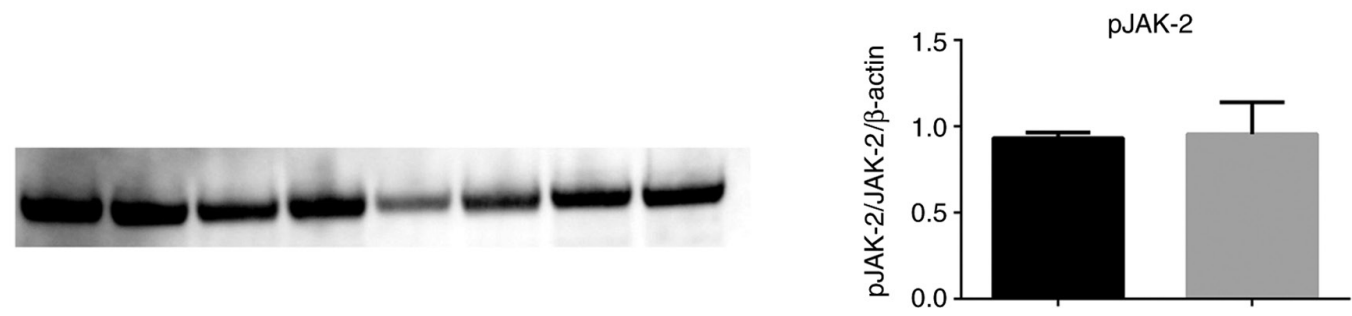

STAT-1

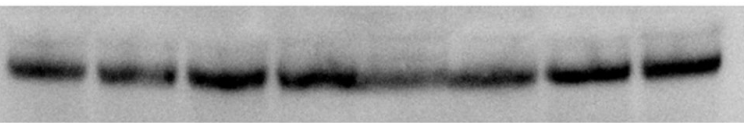

pSTAT-1

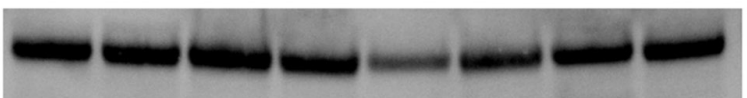

STAT-3
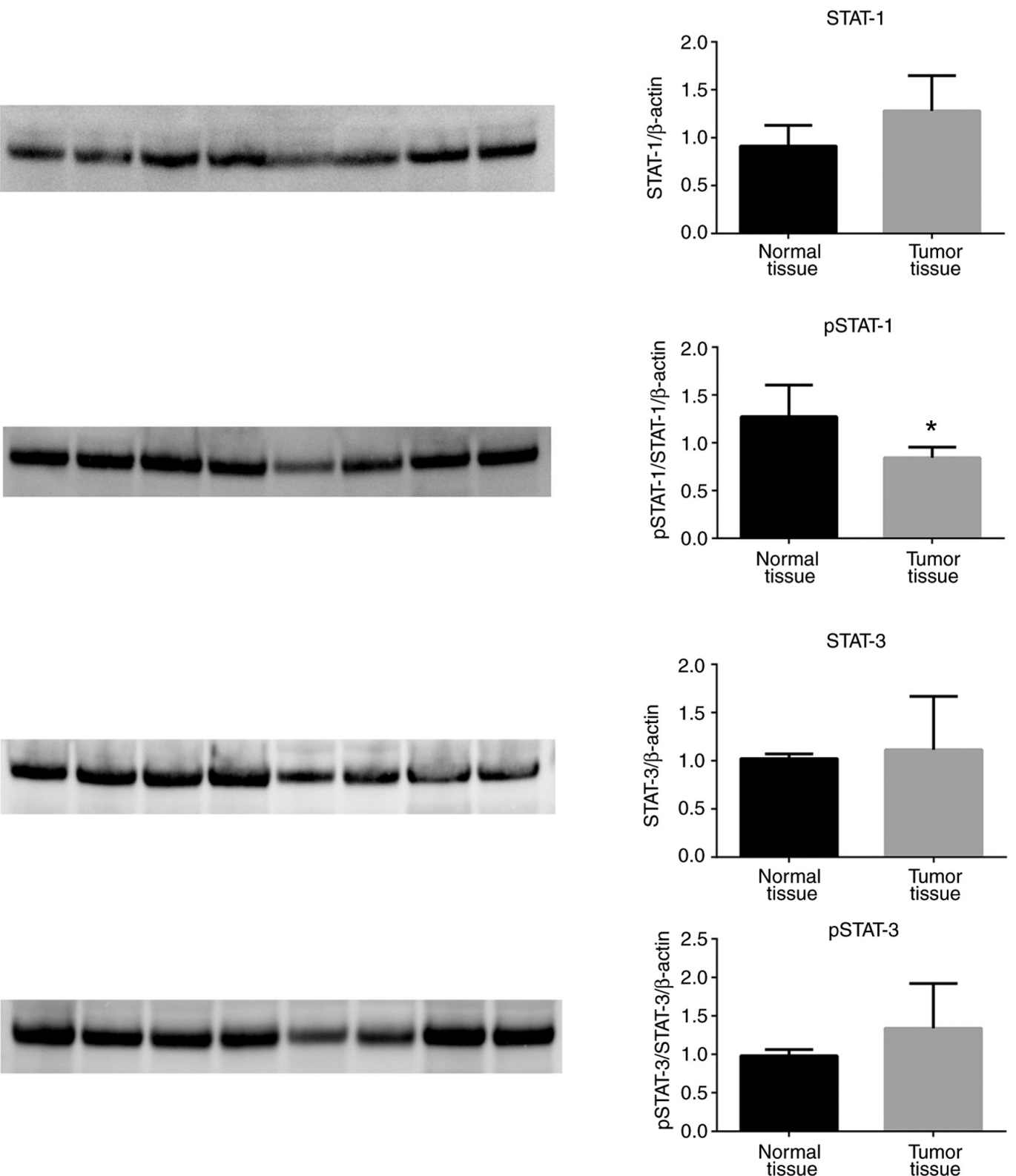

Figure 7. JAK/STAT protein levels in colorectal cancer tissues. JAK-2, pJAK-2, STAT-1, pSTAT-1, STAT-3 and pSTAT-3 protein expression levels in normal and tumor tissues were determined by western blotting. $\beta$-actin was used as a loading control. Data (mean \pm SE) are representative results derived from a minimum of three independent experiments. ${ }^{*} \mathrm{P}<0.05$. p, phosphorylated. 

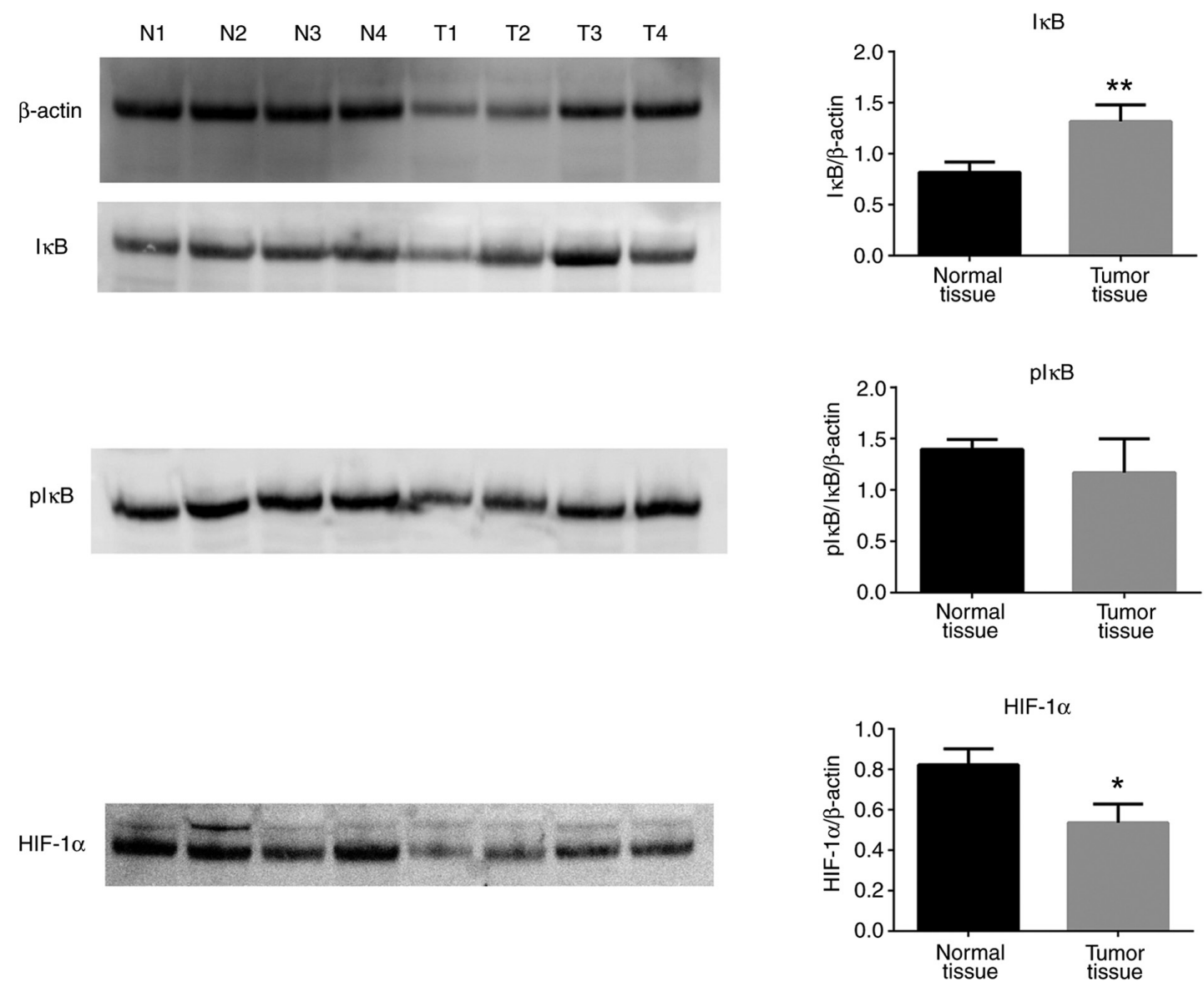

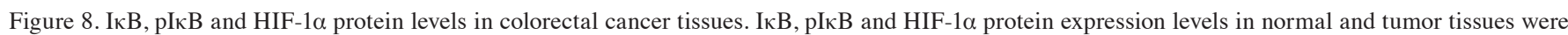
determined by western blotting. $\beta$-actin was used as a loading control. Data (mean \pm SE) are representative results derived from a minimum of three independent experiments. ${ }^{*} \mathrm{P}<0.05$ and ${ }^{* *} \mathrm{P}<0.01$. IкB, inhibitor of $\kappa \mathrm{B} ; \mathrm{HIF}$, hypoxia inducible factor; $\mathrm{p}$, phosphorylated.

A

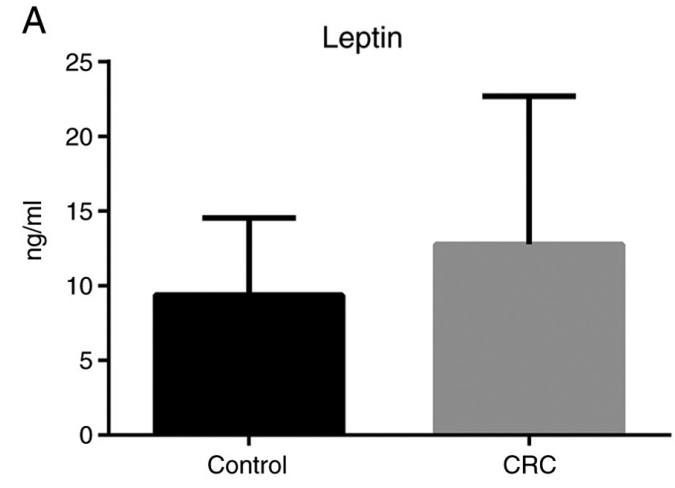

$$
\text { C }
$$

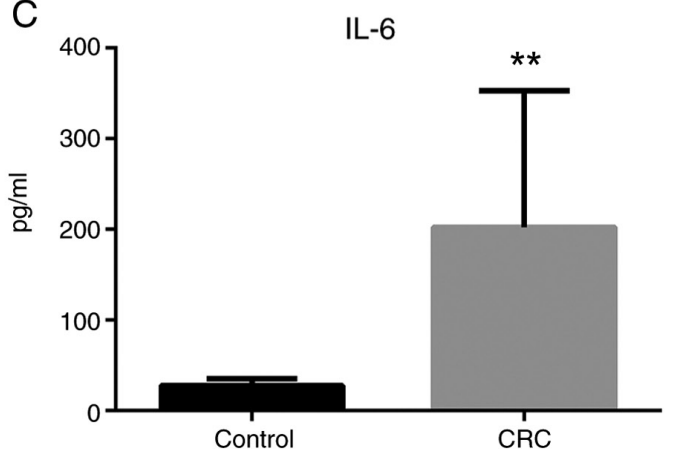

B

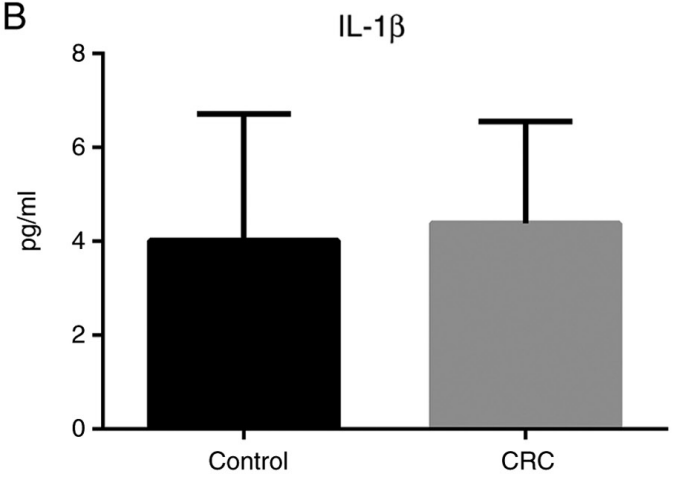

D

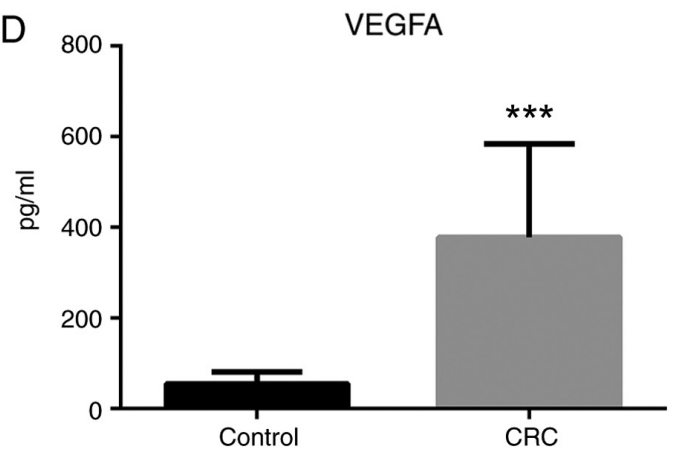

Figure 9. Leptin, IL-1 $\beta$, IL-6, and VEGFA levels in plasma. (A) Leptin, (B) IL-1 $\beta$, (C) IL-6 and (D) VEGFA levels in the plasma of patients with CRC and healthy controls were analyzed by ELISA. Data (mean $\pm \mathrm{SE}$ ) are representative results derived from a minimum of three independent experiments. ${ }^{* *} \mathrm{P}<0.01$ and ${ }^{* * *} \mathrm{P}<0.001$. CRC, colorectal cancer. 
TNF- $\alpha$ and IL-6 synergistically promote colorectal cancer cell growth and cytokine production (22). Migration, invasion, and infiltration of colorectal cancer cells are potentiated by TNF- $\alpha$ (23). Popivanova et al (24) have shown that blocking $\mathrm{TNF}-\alpha$ reduces colorectal carcinogenesis. In the present study, the results demonstrated that TNF- $\alpha$ mRNA expression levels were increased in tumor tissues, while TNFR1 mRNA expression levels were unchanged. TNF- $\alpha$-induced $N F-\kappa B$ regulates the transcription of genes associated with cell growth and proliferation. In resting cells, $\mathrm{NF}-\kappa \mathrm{B}$ is inactive and sequestered in the cytoplasm by inhibitory proteins, such as the inhibitor of $\kappa \mathrm{B}(\mathrm{I} \kappa \mathrm{B})(25)$. NF- $\kappa \mathrm{B}$ is activated through either the classical or alternative pathways. The classical pathway is activated by inflammatory cytokines, IL-1, and TNF $\alpha$. I $\mathrm{B}$ allows NFkB nuclear translocation and activates the transcription of the target genes in the nucleus, which leads to development of inflammation and tumor progression by increasing cell proliferation and migration (26). NF- $\kappa \mathrm{B}$ expression in colorectal cancer is associated with proliferation and angiogenesis and shortened survival $(27,28)$. In the present study, the mRNA expression levels of $N F-\kappa B$ and the protein levels of $\mathrm{I} \kappa \mathrm{B}$ were increased in tumor tissues, whereas there was no significant change in the protein levels of pI $\kappa$ B. These findings indicated that the levels of $\mathrm{NF}-\kappa \mathrm{B}$ in the tumor tissues were increased but activation and translocation of $\mathrm{NF}-\kappa \mathrm{B}$ to the nucleus were inconclusive.

The significance of the present findings is highlighted by the fact that the present study was conducted in human colorectal cancer tissues, and that the results were compatible with the findings of previous studies. The limitations of the present study were that the patients were not classified according to their metastasis status and that there was no detailed immunohistochemical analysis for the NILCO interaction. Further studies will be required in the future with patients classified according to their metastasis status and with detailed functional and protein interaction experimental analyses.

In conclusion, the present study demonstrated that increased levels of leptin, inflammatory cytokines, and the interaction between these molecules may have an important role in colorectal cancer progression. The current findings give valuable information about the intracellular mechanisms related to NILCO, which are essential for tumor biology. Future studies on the inhibition of NILCO may yield novel treatment options for colorectal cancer.

\section{Acknowledgements}

Not applicable.

\section{Funding}

The present study was supported by The Scientific and Technological Research Council of Turkey (TUBITAK; grant no. 116S628).

\section{Availability of data and materials}

The datasets used and/or analyzed during the present study are available from the corresponding author on reasonable request.

\section{Authors' contributions}

$\mathrm{NE}, \mathrm{RO}$ and MO confirm the authenticity of all the raw data. $\mathrm{NE}$ performed the analysis and publication of the results, specifically, RT-qPCR, western blotting experiments and ELISA experiments. RO performed the analysis and publication of the results, specifically, RT-qPCR, western blotting and ELISA experiments. MO performed the analysis and publication of the results, specifically, RT-qPCR, western blotting and ELISA experiments. SE performed the diagnosis of CRC, detection of the sample groups and isolation of the CRC tissue. FY performed the diagnosis of CRC, detection of the sample groups and isolation of the CRC tissue. EI performed the diagnosis of $\mathrm{CRC}$, detection of the sample groups and isolation of the CRC tissue. EvC performed pathological evaluations and diagnoses. FC performed pathological evaluations and diagnoses. ErC performed the analysis and publication of the results. All authors read and approved the final version of the manuscript.

\section{Ethics approval and consent to participate}

The present study was approved by the Ethics Committee of Eskisehir Osmangazi University for Clinical Research (approval no. 80558721/90) and was performed following the ethical standards of The Helsinki Declaration. Tissue specimens from tumor and adjacent normal colon tissues were collected from the Department of General Surgery, Hospital of Eskisehir Osmangazi University, Eskisehir, Turkey. Written consent was obtained from all the subjects participating in the present study.

\section{Patient consent for publication}

Not applicable.

\section{Competing interests}

The authors declare that they have no competing interests.

\section{References}

1. van Kruijsdijk RC, van der Wall E and Visseren FL: Obesity and cancer: The role of dysfunctional adipose tissue. Cancer Epidemiol Biomarkers Prev 18: 2569-2578, 2009.

2. Zhou W, Guo S and Gonzalez-Perez RR: Leptin pro-angiogenic signature in breast cancer is linked to IL-1 signalling. Br J Cancer 104: 128-137, 2011.

3. Gonzalez-Perez RR, Lanier V and Newman G: Leptin's pro-angiogenic signature in breast cancer. Cancers (Basel) 5: 1140-1162, 2013.

4. Guo S and Gonzalez-Perez RR: Notch, IL-1 and leptin crosstalk outcome (NILCO) is critical for leptin-induced proliferation, migration and VEGF/VEGFR-2 expression in breast cancer. PLoS One 6: e21467, 2011.

5. Wang B, Wood IS and Trayhurn P: Hypoxia induces leptin gene expression and secretion in human preadipocytes: Differential effects of hypoxia on adipokine expression by preadipocytes. J Endocrinol 198: 127-134, 2008.

6. Elaraj DM, Weinreich DM, Varghese S, Puhlmann M, Hewitt SM, Carroll NM, Feldman ED, Turner EM and Alexander HR: The role of interleukin 1 in growth and metastasis of human cancer xenografts. Clin Cancer Res 12: 1088-1096, 2006.

7. Lipsey CC,Harbuzariu A, Daley-Brown D and Gonzalez-Perez RR: Oncogenic role of leptin and Notch interleukin-1 leptin crosstalk outcome in cancer. World J Methodol 6: 43-55, 2016. 
8. Daley-Brown D, Harbuzariu A, Kurian AA, Oprea-Ilies G and Gonzalez-Perez RR: Leptin-induced Notch and IL-1 signaling crosstalk in endometrial adenocarcinoma is associated with invasiveness and chemoresistance. World J Clin Oncol 10 222-233, 2019.

9. Lee S, Trivedi U, Johnson C, Farquharson C and Bergkvist GT: Optimised isolation method for RNA extraction suitable for RNA sequencing from feline teeth collected in a clinical setting and at post mortem. Vet Res Commun 43: 17-27, 2019.

10. Rao X, Huang X, Zhou Z and Lin X: An improvement of the $2^{\wedge}$ (-delta delta CT) method for quantitative real-time polymerase chain reaction data analysis. Biostat Bioinforma Biomath 3: 71-85, 2013.

11. Cust AE, Stocks T, Lukanova A, Lundin E, Hallmans G, Kaaks R, Jonsson $\mathrm{H}$ and Stattin P: The influence of overweight and insulin resistance on breast cancer risk and tumour stage at diagnosis: A prospective study. Breast Cancer Res Treat 113: 567-576, 2009.

12. Wei EK, Giovannucci E, Fuchs CS, Willett WC and Mantzoros CS Low plasma adiponectin levels and risk of colorectal cancer in men: A prospective study. J Natl Cancer Inst 97: 1688-1694, 2005.

13. Erkasap N, Ozkurt M, Erkasap S, Yasar F, Uzuner K, Ihtiyar E, Uslu S, Kara M and Bolluk O: Leptin receptor (Ob-R) mRNA expression and serum leptin concentration in patients with colorectal and metastatic colorectal cancer. Braz J Med Biol Res 46: 306-310, 2013.

14. Endo H, Hosono K, Uchiyama T, Sakai E, Sugiyama M, Takahashi H, Nakajima N, Wada K, Takeda K, Nakagama $\mathrm{H}$ and Nakajima A: Leptin acts as a growth factor for colorectal tumours at stages subsequent to tumour initiation in murine colon carcinogenesis. Gut 60: 1363-1371, 2011.

15. Wegler C, Ölander M, Wiśniewski JR, Lundquist P, Zettl K Åsberg A, Hjelmesæth J, Andersson TB and Artursson P: Global variability analysis of mRNA and protein concentrations across and within human tissues. NAR Genom Bioinform 2: lqz010, 2019.

16. Rene Gonzalez R, Watters A, Xu Y, Singh UP, Mann DR, Rueda BR and Penichet ML: Leptin-signaling inhibition results in efficient anti-tumor activity in estrogen receptor positive or negative breast cancer. Breast Cancer Res 11: R36, 2009.

17. Noah TK and Shroyer NF: Notch in the intestine: Regulation of homeostasis and pathogenesis. Annu Rev Physiol 75: 263-288, 2013.
18. Artavanis-Tsakonas S, Rand MD and Lake RJ: Notch signaling: Cell fate control and signal integration in development. Science 284: 770-776, 1999.

19. Baron M: An overview of the Notch signalling pathway. Semin Cell Dev Biol 14: 113-119, 2003.

20. Guilmeau S, Flandez M, Mariadason JM and Augenlicht LH: Heterogeneity of Jagged 1 expression in human and mouse intestinal tumors: Implications for targeting Notch signaling. Oncogene 29: 992-1002, 2010.

21. Shen Y, Wang Q, Zhao Q and Zhou J: Leptin promotes the immune escape of lung cancer by inducing proinflammatory cytokines and resistance to apoptosis. Mol Med Rep 2: 295-299, 2009.

22. De Simone V, Pallone F, Monteleone G and Stolfi C: Role of $\mathrm{T}_{\mathrm{H}} 17$ cytokines in the control of colorectal cancer. Oncoimmunology 2: e26617, 2013

23. Mueller L, von Seggern L, Schumacher J, Goumas F, Wilms C, Braun F and Broering DC: TNF-alpha similarly induces IL-6 and MCP-1 in fibroblasts from colorectal liver metastases and normal liver fibroblasts. Biochem Biophys Res Commun 397: 586-5891, 2010.

24. Popivanova BK, Kitamura K, Wu Y, Kondo T, Kagaya T, Kaneko S, Oshima M, Fujii C and Mukaida N: Blocking TNF-alpha in mice reduces colorectal carcinogenesis associated with chronic colitis. J Clin Invest 118: 560-570, 2008.

25. Pereira SG and Oakley F: Nuclear factor-kappaB1: Regulation and function. Int J Biochem Cell Biol 40: 1425-1430, 2008.

26. Hayden MS and Ghosh S: Signaling to NF-kappaB. Genes Dev 18: 2195-2224, 2004

27. Puvvada SD, Funkhouser WK, Greene K, Deal A, Chu H, Baldwin AS, Tepper JE and O'Neil BH: NF-kB and Bcl-3 activation are prognostic in metastatic colorectal cancer. Oncology 78: 181-188, 2010.

28. Kwon HC, Kim SH, Oh SY, Lee S, Kwon KA, Lee JH, Choi HJ, Park KJ, Lee HS, Roh MS and Kim HJ: Clinicopathological significance of nuclear factor-kappa B, HIF-1 alpha, and vascular endothelial growth factor expression in stage III colorectal cancer. Cancer Sci 101: 1557-1561, 2010.

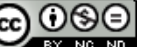

This work is licensed under a Creative Commons Attribution-NonCommercial-NoDerivatives 4.0 International (CC BY-NC-ND 4.0) License. 